\title{
Validity of Type D personality in Iceland: association with disease severity and risk markers in cardiac patients
}

\author{
Erla Svansdottir • Hrobjartur D. Karlsson • \\ Thorarinn Gudnason - Daniel T. Olason • \\ Hordur Thorgilsson • Unnur Sigtryggsdottir • \\ Eric J. Sijbrands · Susanne S. Pedersen · Johan Denollet
}

Received: April 19, 2010/ Accepted: March 7, 2011 / Published online: April 28, 2011

(C) The Author(s) 2011. This article is published with open access at Springerlink.com

\begin{abstract}
Type D personality has been associated with poor prognosis in cardiac patients. This study investigated the validity of the Type D construct in Iceland and its association with disease severity and health-related risk markers in cardiac patients. A sample of 1,452 cardiac patients completed the Type D scale (DS14), and a subgroup of 161 patients completed measurements for the five-factor model of personality, emotional control, anxiety, depression, stress and lifestyle factors. The Icelandic DS14 had good psychometric properties and its construct validity was confirmed. Prevalence of Type D was 26-29\%, and assessment of Type D personality was not confounded by severity of underlying coronary artery disease. Regarding risk markers, Type D patients reported more psychopharmacological medication
\end{abstract}

E. Svansdottir · S. S. Pedersen · J. Denollet $(\bowtie)$

Department of Medical Psychology and Neuropsychology,

Center of Research on Psychology in Somatic

Diseases (CoRPS), Tilburg University,

P.O. Box 90153, 5000 LE Tilburg,

The Netherlands

e-mail: denollet@uvt.nl

URL: http://www.tilburguniversity.nl/corps/

E. Svansdottir

e-mail: e.svansdottir@uvt.nl

S. S. Pedersen

e-mail: s.s.pedersen@uvt.nl

H. D. Karlsson

Icelandic Heart Association, Holtasmára 1,

201 Kópavogur, Iceland

e-mail: hrobjdk@landspitali.is; hrobjartur@hjarta.is

H. Thorgilsson

Landspitali-University Hospital, Hringbraut,

101 Reykjavík, Iceland

e-mail: hordurth@landspitali.is use and smoking, but frequency of previous mental problems was similar across groups. Type D is a valid personality construct in Iceland, and is associated with health-related risk markers, but not cardiac disease severity.

Keywords Personality - Coronary heart disease . DS14 · Validity · Disease severity $\cdot$ Health-related risk markers

\section{Introduction}

Coronary heart disease is one of the leading causes of mortality in the world today (MacKay \& Mensah, 2004;

H. D. Karlsson - T. Gudnason · U. Sigtryggsdottir

Department of Cardiology, Landspitali-University Hospital, Hringbraut, 101 Reykjavík, Iceland

e-mail: unnursig@landspitali.is

H. D. Karlsson - T. Gudnason

Cardiovascular Research Institute of Landspitali and University of Iceland, Landspitali-University Hospital, Hringbraut,

101 Reykjavík, Iceland

e-mail: thorgudn@landspitali.is

D. T. Olason

Department of Psychology, School of Health,

University of Iceland, Oddi v/ Sturlugötu,

101 Reykjavík, Iceland

e-mail: dto@hi.is

E. J. Sijbrands

Departments of Cardiovascular Genetics \& Pharmacology,

Vascular and Metabolic Diseases, Erasmus Medical Center,

Office D435, PO-Box 2040, 3000 CA Rotterdam,

The Netherlands

e-mail: e.sijbrands@erasmusmc.nl 
Murray \& Lopez, 1997), and although new cardiac treatments have helped fight coronary heart disease in recent years, an estimated $1 / 3$ of coronary heart disease risk factors remain elusive (Gudnason, 2004). The addition of psychological factors to standard biomedical risk factors may enhance the prediction of patients at risk. Initial research on the Type A behavior pattern suggested that psychological factors were related to increased risk of heart attacks, but further investigations on Type A behavior were inconclusive (Rozanski et al., 1999). Subsequently, researchers turned their focus towards isolated factors such as hostility, depression, anxiety, social isolation, and chronic stress (Matthews, 2005; Rozanski et al., 1999, 2005; Strike \& Steptoe, 2004) to document a relationship between psychological factors and poor cardiac prognosis (Rozanski et al., 2005).

Clustering of psychological factors within individuals enhances the risk of adverse health outcomes (Rozanski et al., 2005; Strike \& Steptoe, 2004), and this clustering may partly be attributed to a specific vulnerability in the realm of personality (Dimsdale, 2008). The distressed (Type D) personality construct was originally developed to identify cardiac patients who are vulnerable to emotional and interpersonal difficulties (Denollet, 1993; Denollet et al., 1996). Type D individuals tend to experience negative emotions (elevated score on negative affectivity) while not discussing them with others due to fear of rejection (elevated score on social inhibition) (Denollet et al., 1996). Type D personality has been associated with poor quality of life and increased morbidity and mortality in cardiac patients (Denollet et al., 1996, 2006b; Kupper \& Denollet, 2007; Pedersen \& Denollet, 2006). The prevalence of Type D ranges from 28 to $32 \%$ across different cardiovascular conditions, including ischemic heart disease, chronic heart failure, and peripheral artery disease. The mortality risk incurred by Type D is 3 -fold, with this risk being independent of disease severity, such as left ventricular dysfunction, and mood states such as anxiety and depression, and despite appropriate medical treatment (Pedersen \& Denollet, 2006).

The mechanisms relating Type D personality with adverse prognosis in cardiac patients are generally not thought to derive from worse disease severity (de Jonge et al., 2007; Nicholson et al., 2006). Rather, negative health-related behaviors, such as smoking and poor treatment adherence (Kirkcaldy et al., 2002; Pedersen et al., 2007a; Schiffer et al., 2007), and dynamic physiological processes such as elevated cortisol levels (Molloy et al., 2008; Whitehead et al., 2007) and pro-inflammatory cytokines (Denollet et al., 2009) have been suggested as possible contributing factors. Importantly, recent findings have casted doubt on the utility of using extent of coronary atherosclerosis as a surrogate means for inferring associa- tions between psychological risk factors and adverse cardiovascular outcomes in cross-sectional data (Rozanski et al., 2011). In the present study, we included assessment of extent of coronary artery disease to rule out the possibility of reverse causation, whereby disease severity can contribute to greater psychological distress and, in turn, may confound the assessment of Type D personality traits.

In clinical and epidemiological research, Type D can be assessed with the standardized 14-item Type D Scale (DS14) that measures negative affectivity and social inhibition (7 items for each domain) (Denollet, 2005). The DS14 scale has been validated in Belgian (Denollet, 2005), Chinese (Yu et al., 2008), Danish (Pedersen \& Denollet, 2004; Spindler et al., 2009), Dutch (Denollet, 2005), German (Grande et al., 2004), Italian (Gremigni \& Sommaruga, 2004) and Ukrainian (Pedersen et al., 2009) cardiac patients and healthy controls. However, only a few studies have examined how the Type D construct fits within the fivefactor model of personality, and no study to date has tested how the social inhibition factor relates to emotional control. Hence, the objectives of the current study were (a) to evaluate the psychometric properties of the DS14 in Icelandic cardiac patients with a specific focus on the construct validity of Type D, (b) to examine whether assessment of Type $\mathrm{D}$ personality is confounded by worse disease severity in these patients and (c) to explore the association between Type D and health-related risk markers.

\section{Method}

\section{Participants}

This study included two cardiac patient samples. The first sample (cardiac sample I) consisted of 1,291 patients hospitalized for coronary angiography and/or percutaneous coronary intervention at Landspitali-university hospital in Reykjavik (May 2007-June 2008), the only hospital in Iceland where such operations are performed. These patients were approached when hospitalized to the coronary care unit, upon arrival to the emergency ward or by mail if they were on the waiting list for a coronary catheterization. Patients were eligible for participation only if they (a) underwent a coronary angiography or percutaneous coronary intervention during their current hospitalization; and (b) spoke and read Icelandic fluently. Forty-four patients were excluded because they either did not complete the DS14 $(n=34)$ or did not undergo coronary angiography $(n=10)$. The remaining 1,247 patients $(875$ men and 372 women) had a mean age of 64.8 years (SD 10.8), with women being significantly older than men $(M=63.3$ (SD 11.0) vs. $\left.M=68.2(\mathrm{SD} 9.5), t_{(1,245)}=7.57, P<0.001\right)$. This 
patient sample was included in the study to (a) estimate the factor structure of the DS14 scale, and (b) examine whether the assessment of Type D personality is confounded by the severity of underlying coronary artery disease.

The second sample (cardiac sample II) consisted of 161 patients from the coronary care unit, and from the heart failure clinic of the Landspitali-university hospital (February-March 2006 and November 2006-April 2007). This sample was included in the study to examine more extensively the validity of the Type D personality construct in Iceland, and how it is related to health-related risk markers. To this end, these patients completed additional measurements that were not administered in the larger cardiac sample I. Four patients were excluded from analysis due to incomplete questionnaire data. The final sample included 157 participants (118 males and 39 females) with an average age of 61.7 years (SD 11.3), and again women tended to be older than men $(M=60.2$ (SD 11.1) vs. $\left.M=66.4(\mathrm{SD} 11.0), t_{(150)}=3.03, P<0.01\right)$.

Baseline characteristics for the two participant samples are presented in Table 1. Patients in cardiac sample I were older on average compared to patients in cardiac sample II $\left(t_{(1,397)}=3.24 ; P \leq 0.001\right)$, but gender distribution was similar in the two samples $\left(\chi_{(1, n=1,404)}^{2}=1.68, P=0.20\right)$. The majority of patients in cardiac sample I had coronary artery disease $(55 \%)$ or had experienced one or more heart attacks $(23 \%)$, while patients with a history of one or more heart attacks $(41 \%)$ and heart failure $(24 \%)$ were more prominent in cardiac sample II.

The study protocol was approved by the medical ethics committee of the National Bioethics Committee in Iceland. The study was conducted to conform to the ethical tenets developed by the World Medical Association, as espoused

Table 1 Baseline characteristics

\begin{tabular}{lcl}
\hline & $\begin{array}{l}\text { Cardiac sample I } \\
(n=1,247)\end{array}$ & $\begin{array}{l}\text { Cardiac sample II } \\
(n=157)\end{array}$ \\
\hline $\begin{array}{l}\text { Age (years) } \\
\text { Mean (SD) } \\
\text { Gender } \\
\text { Males }\end{array}$ & $64.8(10.8)$ & $61.7(11.3)$ \\
Heart disease & $70 \%(875)$ & $75 \%(118)$ \\
Heart failure & & \\
Pacemaker and & $2 \%(22)$ & $24 \%(38)$ \\
$\quad$ cardiac arrhythmia & $7 \%(89)$ & $11 \%(17)$ \\
$\geq 1$ heart attacks & $23 \%(290)$ & $41 \%(64)$ \\
Coronary artery disease & $55 \%(678)$ & $10 \%(16)$ \\
Hypertension & $7 \%(92)$ & $11 \%(17)$ \\
No disease & $6 \%(73)$ & $0(0 \%)$ \\
Unknown & $0.2 \%(3)$ & $3 \%(5)$ \\
\hline
\end{tabular}

Data are presented as percentages $(n)$ unless otherwise specified in the Declaration of Helsinki. All patients provided written informed consent.

The DS14 scale

The DS14 is a 14-item questionnaire comprised of two seven-item subscales (Denollet, 2005), measuring the tendency to (a) experience negative emotions (negative affectivity) and (b) inhibit self-expression in social interactions (social inhibition). The answering format is on a five-point Likert scale, ranging from 0 (false) to 4 (true), with total scores ranging from 0 to 28 for each subscale. Items include "I am often irritated" (negative affectivity) and "I am a closed kind of person" (social inhibition). The original Dutch DS14 was translated into Icelandic by four researchers. They received aid from two fluent Dutch speakers who independently translated the DS14 items from Dutch to Icelandic; a translation group examined the two independent translations, and one final version was constructed. Subsequently, the final Icelandic version was back-translated and compared to the original Dutch version to ensure accuracy.

Participants were defined as having a Type D personality if they scored $\geq 10$ on both negative affectivity and social inhibition. This cut-off value has been used in previous research (Denollet, 2005; Emons et al., 2007), and is derived from the median split on negative affectivity and social inhibition scores of participants in those studies. A recent study using item-response theory has shown the cutoff $\geq 10$ on both subscales to be the best to distinguish between Type D and non-Type D individuals, as all items had the highest measurement accuracy around that cut-off (Emons et al., 2007).

\section{Construct validity}

To evaluate the construct validity of the Icelandic DS14 scale, the NEO-five-factor inventory (NEO-FFI) (Costa \& McCrae, 1989), emotional control questionnaire (ECQ) (Roger \& Najarian, 1989; Roger \& Nesshoever, 1987), hospital anxiety depression scale (HADS) (Zigmond \& Snaith, 1983) and perceived stress scale (PSS) (Cohen et al., 1983) were administered in Cardiac sample II.

The NEO-FFI is a 60-item self-report scale which assesses five broad personality traits from the five-factor model of personality, that is neuroticism (e.g. anxiety, impulsiveness, vulnerability), extraversion (e.g. sociability, activity, positive emotions), openness (e.g. fantasy, feelings, artistic), agreeableness (e.g. trust, straightforwardness, altruism) and conscientiousness (e.g. achievement striving, dutifulness, self-discipline) (Costa \& McCrae, 1989). The scale contains 12 statements for each 
trait, and respondents answer on a five-point Likert scale (ranging from strongly disagree (0) to strongly agree (4)) how each statement refers to them. The psychometric properties of the Icelandic version of the NEO-FFI are acceptable and the test-retest reliability and internal consistency deemed sufficient (Jónsson, 2005), with Cronbach's alpha ranging from 0.71 to 0.88 for the five traits (Svansdóttir, 2006).

The emotional control questionnaire or ECQ measures how easily people express and control their emotions (Roger \& Najarian, 1989; Roger \& Nesshoever, 1987). The scale includes 56 items which are divided into four factors (emotional inhibition, aggression control, benign control and rehearsal), but in this study a shorter 20 -item version measuring rehearsal and emotional inhibition only was used (Roger et al., 2001). Rehearsal refers to the tendency of individuals to ruminate over emotionally distressing events while emotional inhibition assesses to what extent people express their emotions. The response format for each item ranges from strongly disagree (1) to strongly agree (4). The Icelandic version of this scale has adequate psychometric properties with Cronbach's alpha reliability coefficients of $\alpha=0.83$ for rehearsal and $\alpha=0.74$ for emotional inhibition (Ingibergsdóttir, 2003).

The HADS is a 14-item questionnaire that measures symptoms of depression and anxiety in physically ill people (Zigmond \& Snaith, 1983). The questionnaire contains seven statements for each mood status. Participants rate on a fourpoint scale (0-3) how well each statement refers to them. Total scores range from 0 to 21 for each domain. The Icelandic version of the HADS identifies symptoms of depression and anxiety sufficiently well (Schaaber et al., 1990), with reliability estimates ranging from $\alpha=0.78-0.86$ for anxiety and $\alpha=0.65-0.85$ for depression (Smari et al., 2008).

The PSS or perceived stress scale is a 14-item measure of self-appraised stress (Cohen et al., 1983). Items include for instance "In the last month, how often have you felt that you were unable to control the important things in your life?" The response format is on a five-point Likert scale ranging from never (0) to very often (4), and total scores range from 0 to 56. The scale has good psychometric properties (Cohen et al., 1983; Cohen \& Williamson, 1988) and correlates with social anxiety and depression symptoms (Cohen et al., 1983). The Icelandic version of PSS has comparable psychometric properties to the original language version (Davíðsdóttir \& Bachman, 1991) with Cronbach's alpha $=0.89$ in a university student sample (Svansdóttir, 2006).

\section{Disease severity}

Disease severity, defined by how many coronary arteries were affected by coronary artery disease (i.e. normal arteries, 1, 2, or 3 arteries affected, and main stem narrowing) was derived from results of the coronary angiography in cardiac sample I. Angiography results were inconclusive for one person, which was excluded from this analysis. Information on disease classification, categorized as hypertension, coronary artery disease, previous heart attacks, pacemaker/arrhythmias and heart failure, was obtained from medical staff and/or retrieved from medical records. Information concerning disease classification was missing for three patients in cardiac sample I $(0.2 \%)$ and five patients in cardiac sample II $(3.2 \%)$.

Health-related risk markers

Participants in cardiac sample II provided information by self-report regarding certain health-related risk markers. These included (a) smoking status (never, ex-smoker, current smoker); (b) amount of smoking per day $(0-10$ cigarettes, 10-20 cigarettes, 20-30 cigarettes, and $>30$ cigarettes a day); (c) duration of smoking ( $0-5$ years, 5-10 years, 10-20 years, $>20$ years); (d) previous mental problems, i.e. "Have you experienced any significant mental problems in the past?" (yes, no); and (e) psychopharmacological medication use, i.e. "Have you used one or more of the following medications for more than two weeks in the past 12 months: sleeping pills, anxietyreducing medications, antidepressants and sedatives?" (no, sleeping pills, anxiety-reducing medication, antidepressants, sedatives). Of note, due to a low incidence rate for each medication category, answers were recoded post-hoc to a binary variable containing the following distinction: no, I have not used any of these medications; yes, I have used one or more of these medications.

\section{Statistical analysis}

Principal axis factor analysis with direct oblimin rotation $($ delta $=0)$ was used to explore the factor structure of the DS14, using the scree plot and criterion of eigenvalues $>1$ to determine the number of factors to extract. A confirmatory factor analysis of the scale was performed to confirm the two-factor structure of the scale, using structural equation modeling (SEM) and the maximum likelihood method in AMOS 17 (Analysis of Moment Structures, Chicago, IL, USA). In the construction of the model, the theoretical foundation of the scale was taken into account. As the negative affectivity and social inhibition subscales each cover three different facets of negative affectivity and social inhibition, respectively, error covariance was added to items representing each facet, i.e. for items measuring the negative affectivity facets dysphoria (items 4,7 and 13), worry (items 2 and 12) and irritability (items 5 and 9), and for items measuring the social inhibition facets 
discomfort in social interactions $(6,8$ and 14$)$, reticence (10 and 11) and social poise (items 1 and 3). Goodness of fit indexes used in the analysis included the Chi-square, the Comparative fit index (CIF) and the Root mean square error of approximation (RMSEA). For Chi-square, a value $\geq 0.05$ indicates good fit (agreement with the null hypotheses that residuals are minimal and the data fit the model well). The Chi-square is influenced by sample size, which can lead to inflated Chi-square values and thus statistical significance, indicating bad fit (Schumacker \& Lomax, 2004). For the CFI, values close to 1 indicate a very good fit and values above 0.90 or close to 0.95 good fit. The RMSEA index should be $\leq 0.05$ to indicate good fit, but levels $\leq 0.08$ are considered to indicate adequate fit. Internal consistency of the scale was assessed with Mean inter-item correlation and Cronbach's alpha.

Validity of the DS14 was estimated by exploring the Pearson's correlation between the negative affectivity and social inhibition subscales and similar constructs, i.e. neuroticism and extraversion, emotional inhibition and rehearsal, anxiety and depression and perceived stress. A factor analysis of scale scores on the DS14 scale, NEOFFI, ECQ, HADS and PSS was executed to verify that (a) negative affectivity, neuroticism and rehearsal, and (b) social inhibition, introversion and emotional inhibition measure related constructs, and to test how anxiety, depression and stress would relate to the negative affectivity and social inhibition factors. Differences in disease classification by Type D personality were assessed with Kendall's Tau- $c$ calculations, but patients with arrhythmias and pacemakers were excluded from the analysis due to the different nature of their disease. The Kendall's Tau- $c$ was also employed to estimate differences in disease severity by Type D personality in cardiac sample I, in both the entire sample and among patients who had established coronary artery disease. Finally, Type D and non-Type D patients in cardiac sample II were compared on smoking behavior, prevalence of previous mental problems, and medication use with Chi-square tests for nominal variables and Tau- $c$ for ordinal variables. Association strength was estimated with Cohen's D calculations for quantitative variables and odds ratios for categorical variables. The SPSS 17 statistical software for Windows was used for all main analysis (Statistical Package for Social Sciences, Chicago, IL, USA).

\section{Results}

Factor structure of the DS14

A principal axis factor analysis (direct oblimin rotation, delta $=0)$ in a combined sample of cardiac patients $(n=1,404)$ indicated a two-factor solution, which explained $46 \%$ of variance in the patient sample. These two factors clearly reflected the negative affectivity and social inhibition subscales, with satisfactory factor loadings (ranging from 0.47 to 0.75 ) and good internal consistency (negative affectivity: Cronbach's alpha $=0.85$ and Mean inter-item correlation $=0.45$; social inhibition: Cronbach's alpha $=0.84$, Mean inter-item correlation $=0.43$ ) (Table 2).

A confirmatory factor analysis of the two-factor structure of the Icelandic DS14 in the same sample indicated a good to adequate model fit for the unconstrained model $\left(\chi^{2}=\right.$ 435.63, $P \leq 0.001 ; \mathrm{CFI}=0.953$ and RMSEA $=0.063$, $90 \%$ CI 0.058-0.069). Standardized regressional weights of items to factor ranged from 0.52 to 0.79 for negative affectivity and $0.44-0.80$ for social inhibition (Fig. 1).

\section{Construct validity}

The convergent and construct validity of the Icelandic DS14 scale was evaluated by examining correlations of negative affectivity and social inhibition with similar construct measurements in cardiac sample II. The negative affectivity subscale had a high positive correlation with neuroticism $(r=0.80)$ and rehearsal $(r=0.58)$, while social inhibition was negatively correlated with extraversion $(r=-0.65)$ and positively with emotional inhibition $(r=0.50)$, which further supports the divergent validity of the Type D factors and their individual attributes. Negative affectivity had a high correlation with anxiety, depression and stress scores, indicating that it clearly measures increased negative affect. An axis factor analysis (direct oblimin rotation, delta $=0$ ) of scale scores confirmed that the negative affectivity and social inhibition subscales were differentially related to the five-factor model of personality; negative affectivity (loading $=0.79$ ), neuroticism $(0.78)$ and rehearsal (0.64) loaded on a single negative affectivity/neuroticism factor. Social inhibition $(-0.95)$, extraversion (0.57) and emotional inhibition $(-0.44)$ loaded together on a separate inhibition factor. Neither DS14 subscale was related to agreeableness, conscientiousness or openness of the five-factor model of personality. Anxiety $(-0.50)$, depression $(-0.73)$ and stress $(-0.60)$ loaded together on a single factor termed "psychological wellbeing", but anxiety also had a considerable loading on the negative affectivity/neuroticism factor (0.49) (Table 3).

\section{Prevalence of Type D personality}

Average scores on negative affectivity and social inhibition were equivalent in the two patient samples (negative affectivity: $M=8.6$ (SD 5.6) vs. $M=8.8$ (SD 5.9), 
Table 2 Factor analysis and reliability of the DS14 scale in a combined cardiac sample $(n=1,404)$
The highest loadings on the corresponding factor, Cronbach's alpha and mean inter-item correlations are presented in bold

\begin{tabular}{lrr}
\hline Factors & I & II \\
\hline Negative affectivity items & & \\
2. I often make a fuss about unimportant things & $\mathbf{0 . 6 1}$ & 0.10 \\
4. I often feel unhappy & $\mathbf{0 . 7 4}$ & 0.07 \\
5. I am often irritated & $\mathbf{0 . 7 3}$ & 0.04 \\
7. I take a gloomy view of things & $\mathbf{0 . 6 3}$ & -0.14 \\
9. I am often in a bad mood & $\mathbf{0 . 5 8}$ & -0.13 \\
12. I often worry about something & $\mathbf{0 . 6 0}$ & 0.02 \\
13. I am often down in the dumps & $\mathbf{0 . 7 3}$ & -0.12 \\
Cronbach's alpha & $\mathbf{0 . 8 5}$ & $\mathbf{0 . 4 5}$ \\
Mean inter-item correlation & & $\mathbf{0 . 7 2}$ \\
Social inhibition items & 0.14 & $\mathbf{0 . 6 1}$ \\
1. I make contact easily when I meet people & 0.16 & $-\mathbf{0 . 5 0}$ \\
3. I often talk to strangers & 0.29 & $\mathbf{0 . 7 5}$ \\
6. I often feel inhibited in social interactions & 0.10 & $\mathbf{- 0 . 6 6}$ \\
8. I find it hard to start a conversation & 0.12 & $\mathbf{0 . 4 7}$ \\
10. I am a closed kind of person & 0.16 & $-\mathbf{0 . 6 9}$ \\
11. I would rather keep other people at a distance & 0.15 & $\mathbf{0 . 8 4}$ \\
14. When socializing I don't find the right things to talk about & & $\mathbf{0 . 4 3}$ \\
Cronbach's alpha & & \\
Mean inter-item correlation & &
\end{tabular}

$t_{(1,402)}=0.46, P=0.65$; social inhibition: $M=9.3(\mathrm{SD}$ 5.8 ) vs. $M=9.3$ (SD 6.1), $t_{(1,402)}=0.11, P=0.91$; for cardiac sample I and II, respectively). Using the cutoff $\geq 10$ for both subscales (Denollet, 2005; Emons et al., 2007), $26 \%$ of patients in cardiac sample I and $29 \%$ of patients in cardiac sample II, were classified as Type D individuals.

\section{Confounding effect of disease severity}

Assessment of Type D personality was not confounded by severity of underlying coronary artery disease in cardiac sample I, as estimated by number of arteries affected by coronary artery disease from the coronary angiography results $($ Tau- $c=0.010, n=1,237, P=0.72$; Fig. 2). About $1 / 3$ of both non-Type D and Type D patients had normal arteries or atheroma with no significant occlusions, and with those individuals excluded from the analysis, Type D personality was still not associated with worse disease severity (Tau- $c=-0.001, n=838, P=0.98$ ).

Assessment of Type D personality was also not related to disease classification in cardiac sample I (Tau- $c=$ $-0.02, n=1,155, P=0.45$ ) nor cardiac sample II (Tau$c=-0.15, n=135, P=0.068)$. In both cases, disease classification was categorized as: no disease, hypertension, coronary artery disease, $\geq 1$ heart attacks and heart failure.
Association with health-related risk markers

As a final step, we explored the relationship of Type D personality with psychopharmacological medication use, previous mental problems and smoking in cardiac sample II. Type D patients reported more psychopharmacological medication use (Fig. 3). When asked about use of sleeping pills, anxiety-reducing medication, antidepressants and sedatives, half of the cardiac patients with a Type D personality $(51 \%)$ reported having used one or more of these medications compared to $29 \%$ of their non-Type D counterparts $\left(\chi_{(1, n=154)}^{2}=6.79, P=0.009 ;\right.$ OR $2.59,95 \% \mathrm{CI}$ 1.25-5.34, $P=0.010)$. Prevalence of previous mental problems did however not differ between Type D (19\%) and non-Type D (14\%) patients $\left(\chi_{(1, n=149)}^{2}=0.584\right.$, $P=0.45)$. Type D patients were significantly more likely to smoke as compared with non-Type D patients (Fig. 3); i.e., $22 \%$ versus $6 \%\left(\chi_{(1, n=156)}^{2}=8.35, P=0.004\right.$; OR $4.25,95 \%$ CI $1.50-12.00, P=0.006)$. In patients with a history of smoking, no differences were found between Type Ds and non-Type Ds regarding how many cigarettes they smoked per day (Tau- $c=0.11, n=115, P=0.26$ ). However, a trend towards a longer history of smoking was noted in Type Ds (Tau- $c=0.15, n=120 ; P=0.056$ ), but $76 \%$ of Type D smokers (former or current) reported having smoked for 20 years or more compared to $59 \%$ of non-Type D smokers. 
Fig. 1 Standardized regression weights for the 2 -factor model of the DS14, representing negative affectivity $(N A)$ and social inhibition (SI)

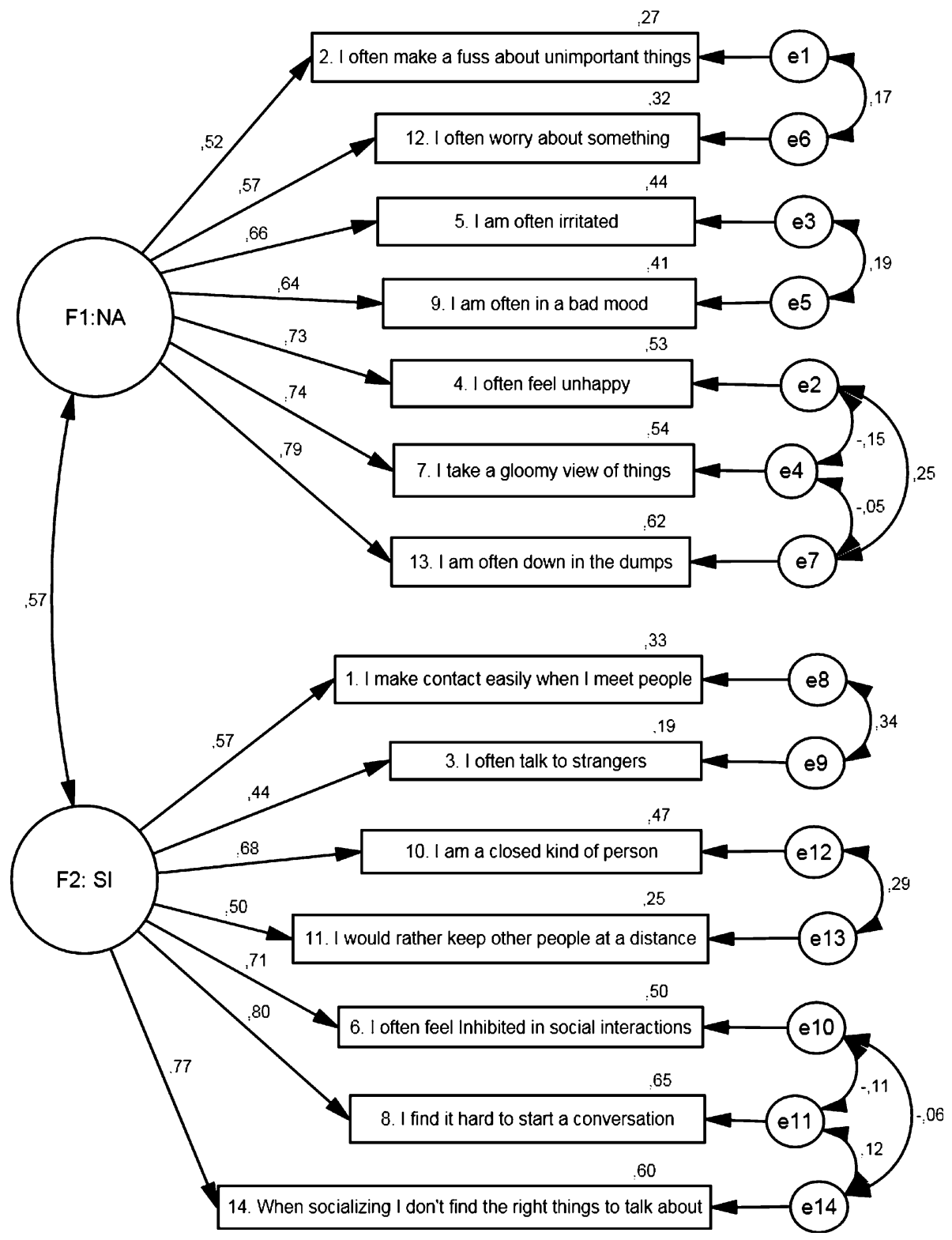

\section{Discussion}

The objectives of the current study were to evaluate the psychometric properties and construct validity of the Icelandic DS14 scale, to test whether Type D assessment is confounded by disease severity in Icelandic angiography patients, and to explore the relationship between Type D and health-related risk markers. The findings supported the two-factor structure of the Icelandic DS14, and its validity and reliability in this sample of Icelandic heart patients. Principal axis factor analysis revealed internally consistent negative affectivity and social inhibition factors, and a confirmatory factor analysis confirmed the two-factor structure of the original scale (Denollet, 2005) in a large sample of Icelandic cardiac patients.
The current results supported the convergent and divergent validity of the Type D construct in the Icelandic setting. An exploratory factor analysis of scale scores showed that negative affectivity, neuroticism and rehearsal loaded on the same factor, while social inhibition, extraversion, and emotional inhibition loaded together on another factor, supporting the construct validity of the two factors of the DS14 (Denollet, 2005; Fruyt \& Denollet, 2002) whilst also strengthening its cross-cultural validity. Furthermore, negative affectivity correlated strongly with anxiety, depression and moderately with perceived stress, confirming the presence of increased negative mood states within the negative affectivity trait. In addition, social inhibition was clearly associated with emotional inhibition as measured by the emotional control scale. In a recent 
Table 3 Correlations and results of a factor analysis of scale scores for the DS14, NEO-FFI, ECQ and HADS subscales and PSS scale

\begin{tabular}{|c|c|c|c|c|c|c|c|}
\hline \multirow{2}{*}{$\begin{array}{l}\text { Correlation } \\
\text { Cardiac sample II }(n=157)\end{array}$} & \multirow[t]{2}{*}{ Negative affectivity } & \multirow[t]{2}{*}{ Social inhibition } & \multicolumn{5}{|c|}{ Pattern matrix } \\
\hline & & & I & II & III & IV & $\mathrm{V}$ \\
\hline Negative affectivity & - & $0.47 *$ & 0.79 & -0.14 & -0.09 & -0.07 & 0.04 \\
\hline Social inhibition & - & - & 0.11 & -0.95 & 0.11 & -0.05 & 0.05 \\
\hline Neuroticism & $0.80 *$ & $0.47 *$ & 0.78 & -0.12 & -0.06 & -0.14 & -0.13 \\
\hline Extraversion & $-0.48^{*}$ & $-0.65^{*}$ & -0.09 & 0.57 & 0.12 & -0.02 & 0.17 \\
\hline Agreeableness & $-0.33^{*}$ & $-0.21^{*}$ & -0.28 & -0.03 & 0.07 & -0.35 & 0.17 \\
\hline Conscientiousness & $-0.20 *$ & $-0.25^{*}$ & -0.01 & 0.06 & 0.05 & 0.12 & 0.72 \\
\hline Openness & -0.02 & -0.07 & -0.02 & 0.06 & 0.01 & -0.45 & -0.09 \\
\hline Rehearsal & $0.58^{*}$ & $0.35 *$ & 0.64 & -0.05 & 0.01 & 0.23 & -0.02 \\
\hline Emotional inhibition & $0.25^{*}$ & $0.50 *$ & -0.08 & -0.44 & -0.19 & 0.25 & -0.10 \\
\hline Anxiety & $0.67 *$ & $0.26^{*}$ & 0.49 & 0.01 & -0.50 & -0.25 & 0.20 \\
\hline Depression & $0.55^{*}$ & $0.35 *$ & 0.04 & -0.15 & -0.73 & -0.11 & -0.09 \\
\hline Perceived stress & $0.38^{*}$ & $0.18 *$ & 0.04 & 0.05 & -0.60 & 0.23 & -0.09 \\
\hline
\end{tabular}

The highest loadings on the corresponding factor are presented in bold

NEO-FFI NEO-five-factor inventory, ECQ Emotional control questionnaire, HADS Hospital anxiety and depression scale, PSS Perceived stress scale

$* P<0.001$

Fig. 2 Coronary artery disease severity, stratified by Type D personality

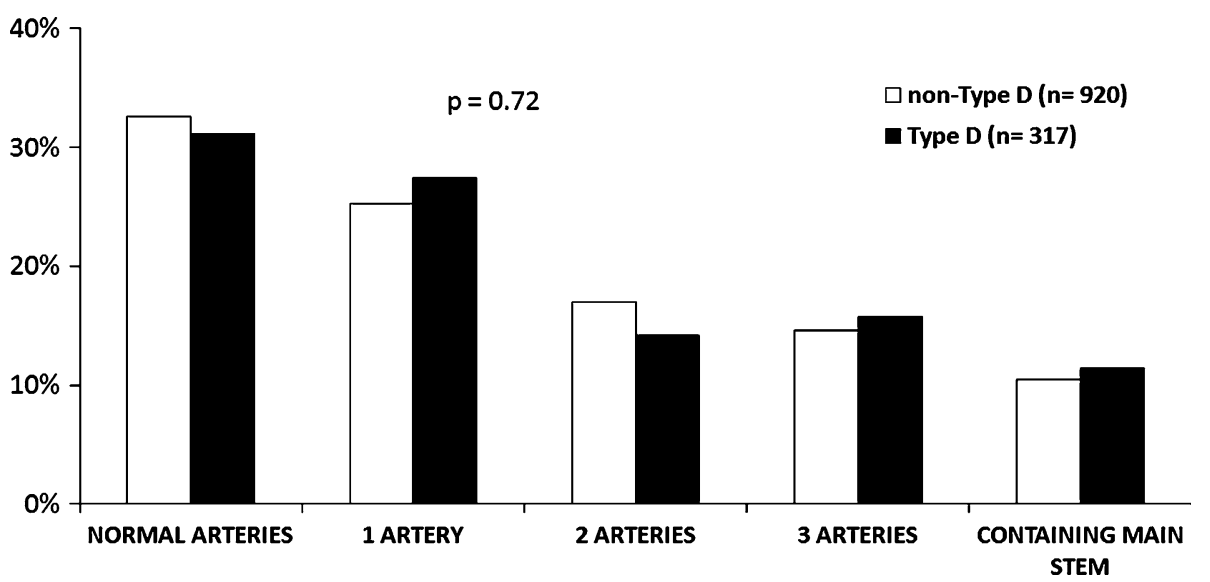

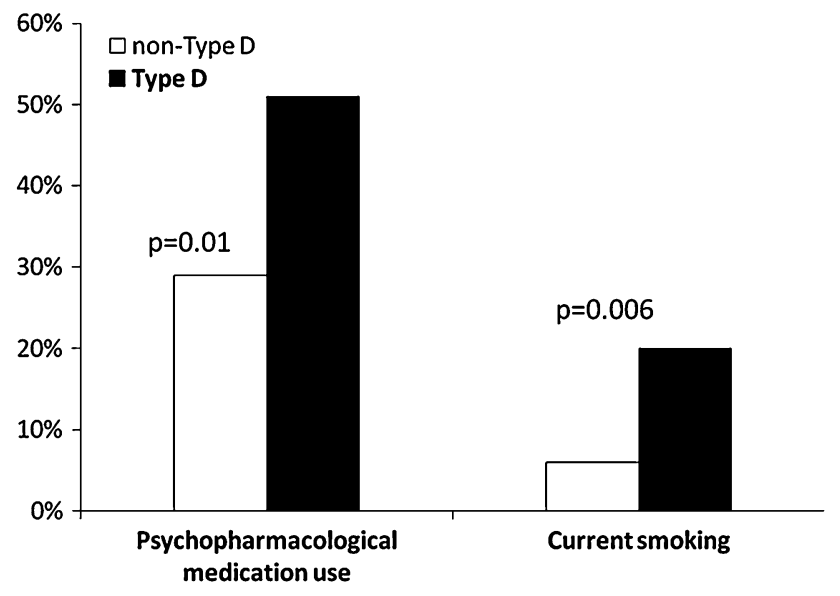

Fig. 3 Prevalence of psychopharmacological medication use and smoking, stratified by Type D personality study, Grande et al. (2010) advocated more testing of the construct validity of the social inhibition dimension, especially since it is the combination of social inhibition with negative affectivity that seems to make Type D personality a stronger predictor of adverse cardiac events compared with other single-dimensional negative affect factors, such as depression. In the context of Type D personality, the inhibition of emotions in social interaction is believed to play a key part in the association with adverse cardiac prognosis, by modulating the effect negative emotions have on cardiac prognosis (Denollet et al., 2006a). Others have also linked social inhibition with social avoidance (Yu et al., 2008), lack of social boldness (Grande et al., 2010) and suppressed anger (Denollet et al., 2010a). 
The prevalence of Type D personality of twenty-six and twenty-nine percent in the cardiac samples was comparable to that found in European and Chinese samples (Denollet, 2005; Grande et al., 2004; Gremigni \& Sommaruga, 2004; Pedersen \& Denollet, 2004; Pedersen et al., 2009; Spindler et al., 2009; Yu et al., 2008). Assessment of Type D personality was not confounded by disease severity, as estimated by the number of coronary arteries affected with coronary artery disease and/or presence of significant narrowing at the main stem. This finding is in accordance with previous results in coronary artery disease and congestive heart failure patients, where no association has been found between Type D personality and indicators of disease severity, such as multivessel disease (Martens et al., 2007), left ventricular ejection fraction (Denollet \& Brutsaert, 1998; de Jonge et al. 2007) and biomedical markers (i.e. brain natriuretic peptide) (Pelle et al., 2009). Similarly, Type D personality was not related to disease classification in either of the cardiac samples. The majority of former findings have generally also revealed that Type D personality is stable across time, and does not seem to be affected by changes in mood status or severity of cardiac disease (Martens et al., 2007).

The lack of association between Type D personality and extent of coronary artery disease does not necessarily diminish the status of Type D personality as a predictor for adverse cardiac prognosis. Conversely, these findings may merely indicate that the mechanisms relating Type D personality with adverse prognosis do not stem from worse disease severity, but through other pathways. Furthermore, if disease severity were in fact the pathway through which Type D personality affects cardiac prognosis, then the association between Type $\mathrm{D}$ and prognosis should diminish in strength or disappear altogether when multivariate adjustments for disease severity markers are conducted. This has however not been the case in previous studies, as is evident in the recent review by Denollet et al. (2010b). Mediating mechanisms linking Type D with adverse cardiac prognosis reside more likely in behavioral and physiological processes. Potential behavioral factors include unhealthy lifestyle behaviors (Williams et al., 2008), more smoking (Pedersen et al., 2007a), poor treatment adherence (Rozanski et al., 2005; Williams et al., 2011) and inadequate consultation behavior (Schiffer et al., 2007), while physiological and biological processes may include elevated cortisol (Molloy et al., 2008; Whitehead et al., 2007), pro-inflammatory cytokines (Denollet et al., 2009) and cardiovascular stress reactivity (Denollet et al., 2010b) to name a few. Type D patients may thus be less likely to follow their doctors recommendations regarding medications or changing unhealthy lifestyle behaviors, and perhaps less efficient in presenting their symptoms to their doctor, due to their high social inhibition. Such factors could possibly explain why these patients develop or experience a more adverse prognosis compared to their non-Type D counterparts.

A recent study by Rozanski et al. (2011) has also reported that psychological risk factors (depression, hostility, social support, perceived stress, job strain, and optimism) were not associated with the extent of coronary atherosclerosis. This further supports the lack of association between Type D and extent of coronary artery disease in the current study, as the Type D construct generally summarizes such psychological risk factors in the general negative emotional distress it encompasses (Suls \& Bunde, 2005). Finally, even as some researchers have disputed that the relation of psychological factors with cardiovascular prognosis is confounded by worse somatic health, findings from a recent study have indicated that the Type D personality construct is less confounded by somatic health compared with depression (de Jonge et al. 2007).

Type D personality had strong ties to health-related risk markers in cardiac patients. Although no association was found between Type D personality and prevalence of reported previous mental problems in the current study, psychopharmacological medication use was higher among Type D patients compared to their non-Type D counterparts, and a high correlation emerged between negative affectivity and anxiety and depression. Previously, researchers have also found that post-myocardial infarction patients with a Type D personality were significantly more likely to use benzodiazepines as compared to non-Type D patients (Denollet et al., 1995). The lack of association with former mental problems seems contradictory with the high correlation noted between negative affectivity and anxiety and depression. The assessment of previous mental problems may not adequately portray the number of previously diagnosed mental problems, due to the simplistic one question format assessment.

We also found a relationship between Type D personality and smoking among cardiac patients. Incidence of current smoking was higher in the Type D patient group, and there were some indications that Type D smokers had a longer history of smoking compared to non-Type D smokers. Previously, it has been reported that cardiac patients with a Type D personality may be more likely to smoke (Pedersen et al., 2007b), and that Type D individuals are less likely to engage in healthy lifestyle behaviors (Williams et al., 2008). These findings suggest that cardiac patients with Type D personality may struggle more with the lifestyle changes recommended by doctors to decrease likelihood of further cardiac events. In addition, previous results have indicated that heart failure patients with Type D personality are more likely to show inadequate consultation behavior compared to non-Type D patients (Pelle et al., 2010; Schiffer et al., 2007), which implies that self-management 
and medical adherence in these patients may be impaired as well. Nevertheless, research results have indicated that the adverse effect of Type D on cardiac prognosis (Pedersen et al., 2007b) and poor health status (Pedersen et al., 2007a) remains significant despite statistical adjustment for smoking and other mechanisms that may mediate the relationship between Type D and health outcomes. More research needs to be conducted to clarify which mediating mechanisms are behind Type D's association with adverse prognosis in cardiac patients, and to determine whether health-behavior and/or poor medical adherence play a significant role.

Certain limitations restrict the interpretation of the present findings. First of all, the participant samples were not randomly selected. Yet, cardiac sample I included consecutive patients nationwide in Iceland, which diminished greatly the risk of selection bias in that sample. Another limitation is the self-report of psychopharmacological medication use, previous mental health problems and smoking, and the unavailability of these measures from cardiac sample I.

Overall, the results of the present study indicated that the Icelandic DS14 is a psychometrically sound assessment tool that can be readily applied in epidemiological and clinical research. The Type D personality construct was prevalent in Icelandic cardiac patients, not confounded by disease severity, and related to certain health-related risk markers in this clinical population.

Acknowledgments The present research was supported by Rannís, The Icelandic Centre for Research (Reykjavík, Iceland) by a grant to Dr. Hrobjartur D. Karlsson, the Landspitali-University Hospital Research found, Iceland, with a grant to the project, and by the Netherlands Organisation for Scientific Research (The Hague, The Netherlands) with a VICI grant (453-04-004) to Dr. Johan Denollet and a VENI grant (451-05-001) to Dr. Susanne S. Pedersen.

Conflict of interest There is no conflict of interest related to this study.

Open Access This article is distributed under the terms of the Creative Commons Attribution Noncommercial License which permits any noncommercial use, distribution, and reproduction in any medium, provided the original author(s) and source are credited.

\section{References}

Cohen, S., Kamarck, T., \& Mermelstein, R. (1983). A global measure of perceived stress. Journal of Health and Social Behavior, 24, 385-396.

Cohen, S., \& Williamson, G. (1988). Perceived stress in a probability sample of the United States. In S. Spacapan \& S. Oskamp (Eds.), The social psychology of health: Claremont symposium on applied social psychology (pp. 31-67). Newsbury Park, CA: Sage.

Costa, P. T., \& McCrae, R. R. (1989). The NEO-PI/NEO-FFI manual supplement. Odessa, FL: Psychological Assessment Resources.
Davíðsdóttir, S., \& Bachman, T. (1991). Tengsl streitu og kynferðis við heilsufar og heilsuvenjur [Association of stress and gender with health and health-habits]. Unpublished Bachelor's thesis, University of Iceland, Reykjavik, Iceland.

de Jonge, P., Denollet, J., van Melle, J. P., Kuyper, A., Honig, A., Schene, A. H., et al. (2007). Associations of Type D personality and depression with somatic health in myocardial infarction patients. Journal of Psychosomatic Research, 63, 477-482.

Denollet, J. (1993). Biobehavioral research on coronary heart disease: Where is the person? Journal of Behavioral Medicine, 16, $115-142$.

Denollet, J. (2005). DS14: Standard assessment of negative affectivity, social inhibition, and Type D personality. Psychosomatic Medicine, 67, 89-97.

Denollet, J., \& Brutsaert, D. L. (1998). Personality, disease severity, and the risk of long-term cardiac events in patients with a deceased ejection fraction after myocardial infarction. Circulation, 97, 167-173.

Denollet, J., Gidron, Y., Vrints, C. J., \& Conraads, V. M. (2010a). Anger, suppressed anger, and risk of adverse events in patients with coronary artery disease. American Journal of Cardiology, 105, 1555-1560.

Denollet, J., Pedersen, S. S., Ong, A. T., Erdman, R. A., Serruys, P. W., \& van Domburg, R. T. (2006a). Social inhibition modulates the effect of negative emotions on cardiac prognosis following percutaneous coronary intervention in the drug-eluting stent era. European Heart Journal, 27, 171-177.

Denollet, J., Pedersen, S. S., Vrints, C. J., \& Conraads, V. M. (2006b). Usefulness of Type D personality in predicting five-year cardiac events above and beyond concurrent symptoms of stress in patients with coronary heart disease. American Journal of Cardiology, 97, 970-973.

Denollet, J., Schiffer, A. A., Kwaijtaal, M., Hooijkaas, H., Hendriks, E. H., Widdershoven, J. W., et al. (2009). Usefulness of Type D personality and kidney dysfunction as predictors of interpatient variability in inflammatory activation in chronic heart failure. American Journal of Cardiology, 103, 399-404.

Denollet, J., Schiffer, A. A., \& Spek, V. (2010b). A general propensity to psychological distress affects cardiovascular outcomes: Evidence from research on the Type D (distressed) personality profile. Circulation: Cardiovascular Quality and Outcomes, 3, 546-557.

Denollet, J., Sys, S. U., \& Brutsaert, D. L. (1995). Personality and mortality after myocardial infarction. Psychosomatic Medicine, 57, 582-591.

Denollet, J., Sys, S., Stroobant, N., Rombouts, H., Gillebert, T., \& Brutsaert, D. (1996). Personality as independent predictor of long-term mortality in patients with coronary heart disease. Lancet, 347, 417-421.

Dimsdale, J. E. (2008). Psychological stress and cardiovascular disease. Journal of the American College of Cardiology, 51, $1237-1246$.

Emons, W. H. M., Meijer, R. R., \& Denollet, J. (2007). Negative affectivity and social inhibition in cardiovascular disease: Evaluating type-D personality and its assessment using item response theory. Journal of Psychosomatic Research, 63, 27-39.

Fruyt, F., \& Denollet, J. (2002). Type D personality: A five-factor model perspective. Psychology \& Health, 17, 671-683.

Grande, G., Glaesmer, H., \& Roth, M. (2010). The construct validity of social inhibition and the Type-D taxonomy. Journal of Health Psychology, 15, 1103-1112.

Grande, G., Jordan, J., Kümmel, M., Struwe, C., Schubmann, R., Schulze, F., et al. (2004). Evaluation der deutschen Typ-D-Skala (DS14) und Prävalenz der Typ-D-Persönlichkeit bei kardiologischen und psychosomatischen Patienten sowie Gesunden [Evaluation of the German Type D scale (DS14) and prevalence 
of the Type D personality pattern in cardiological and psychosomatic patients and healthy subjects]. Psychotherapie, Psychosomatik, Medizinische Psychologie, 54, 413-422.

Gremigni, P., \& Sommaruga, M. (2004). Pesonalità di Tipo D, un costrutto rilevante in cardiologia. Studio preliminare di validazione del questionario italiano [Type D personality, a relevant construct in cardiology. Preliminary validation study of the Italian questionnaire]. Psicoterapia Cognitiva e Comportamentale, $11,7-18$.

Gudnason, V. (2004). Priðjungur áhættu ennpá óutskýrður [A third of risk yet unexplained]. Hjartavernd, 39, 15-16.

Ingibergsdóttir, S. (2003). Orð eru til alls fyrst. Áhrif tjáningar tilfinninga a' heilsufar hjartasjuklinga [Words are the beginning: The influence of expressing emotions on the health of cardiac patients]. Unpublished cand psych thesis, University of Iceland, Reykjavík, Iceland.

Jónsson, F. H. (2005). Próffræðilegir eiginleikar íslenskrar útgáfu NEO-FFI-R [The psychometric properties of the Icelandic version of the NEO-FFI-R]. In Ú. Hauksson (Ed.), Rannsóknir í Félagsvisindum VI (pp. 429-439). Reykjavík, Iceland: Félagsvísindastofnun Háskóla Íslands.

Kirkcaldy, B. D., Shephard, R. J., \& Siefen, R. G. (2002). The relationship between physical activity and self-image and problem behaviour among adolescents. Social Psychiatry and Psychiatric Epidemiology, 37, 544-550.

Kupper, N., \& Denollet, J. (2007). Type D personality as a prognostic factor in heart disease: Assessment and mediating mechanisms. Journal of Personality Assessment, 89, 265-276.

MacKay, J., \& Mensah, J. (2004). The atlas of heart disease and stroke. Geneva: WHO.

Martens, E. J., Kupper, N., Pedersen, S. S., Aquarius, A. E., \& Denollet, J. (2007). Type D personality is a stable taxonomy in post-MI patients over an 18-month period. Journal of Psychosomatic Research, 63, 545-550.

Matthews, K. (2005). Psychological perspectives on the development of coronary heart disease. American Psychologist, 60, 783-796.

Molloy, G. J., Perkins-Porras, L., Strike, P. C., \& Steptoe, A. (2008). Type-D personality and cortisol in survivors of acute coronary syndrome. Psychosomatic Medicine, 70, 863-868.

Murray, C. J., \& Lopez, A. D. (1997). Mortality by cause for eight regions of the world: Global burden of disease study. Lancet, $349,1269-1276$

Nicholson, A., Kuper, H., \& Hemingway, H. (2006). Depression as an aetiologic and prognostic factor in coronary heart disease: A meta-analysis of 6362 events among 146538 participants in 54 observational studies. European Heart Journal, 27, 2763-2774.

Pedersen, S. S., \& Denollet, J. (2004). Validity of the Type D personality construct in Danish post-MI patients and healthy controls. Journal of Psychosomatic Research, 57, 265-272.

Pedersen, S. S., \& Denollet, J. (2006). Is Type D personality here to stay? Emerging evidence across cardiovascular disease patient groups. Current Cardiology Reviews, 2, 205-213.

Pedersen, S. S., Denollet, J., Ong, A. T., Serruys, P. W., Erdman, R. A., \& van Domburg, R. T. (2007a). Impaired health status in Type D patients following PCI in the drug-eluting stent era. International Journal of Cardiology, 114, 358-365.

Pedersen, S. S., Denollet, J., Ong, A. T., Sonnenschein, K., Erdman, R. A., Serruys, P. W., et al. (2007b). Adverse clinical events in patients treated with sirolimus-eluting stents: The impact of Type D personality. European Journal of Cardiovascular Prevention and Rehabilitation, 14, 135-140.

Pedersen, S. S., Yagensky, A., Smith, O., Yagenska, O., Shpak, V., \& Denollet, J. (2009). Preliminary evidence for the cross-cultural utility of the Type D personality construct in the Ukraine. International Journal of Behavioral Medicine, 16, 108-115.
Pelle, A. J., Schiffer, A. A., Smith, O. R., Widdershoven, J. W., \& Denollet, J. (2010). Inadequate consultation behavior modulates the relationship between Type D personality and impaired health status in chronic heart failure. International Journal of Cardiology, 142, 65-71.

Pelle, A. J. M., van den Broek, K. C., Szabo, B. M., \& Kupper, N. (2009). The relationship between Type D personality and chronic heart failure is not confounded by disease severity as assessed by BNP. International Journal of Cardiology, 145, 82-83. doi:10.1016/j.ijcard.2009.1005.1018.

Roger, D., de la Banda, G. G., Lee, H. S., \& Olason, D. T. (2001). A factor-analytic study of cross-cultural differences in emotional rumination and emotional inhibition. Personality and Individual Differences, 31, 227-238.

Roger, D., \& Najarian, B. (1989). The construction and validation of a new scale for measuring emotion control. Personality and Individual Differences, 10, 845-853.

Roger, D., \& Nesshoever, W. (1987). The constructional and preliminary validation of a scale for measuring emotional control. Personality and Individual Differences, 8, 527-534.

Rozanski, A., Blumenthal, J., Davidson, K., Saab, P., \& Kubzansky, L. (2005). The epidemiology, pathophysiology, and management of psychosocial risk factors in cardiac practice: The emerging field of behavioral cardiology. Journal of the American College of Cardiology, 45, 637-651.

Rozanski, A., Blumenthal, J., \& Kaplan, J. (1999). Impact of psychological factors on the pathogenesis of cardiovascular disease and implications for therapy. Circulation, 99, 2192-2217.

Rozanski, A., Gransar, H., Kubzansky, L. D., Wong, N., Shaw, L., Miranda-Peats, R., et al. (2011). Do psychological risk factors predict the presence of coronary atherosclerosis? Psychosomatic Medicine, 73, 7-15.

Schaaber, U. L., Smari, J., \& Oskarsson, H. (1990). Comparison of the hospital anxiety and depression rating scale (HAD) with other depression and anxiety rating scales. Nordic Journal of Psychiatry, 44, 507-512.

Schiffer, A. A., Denollet, J., Widdershoven, J. W., Hendriks, E. H., \& Smith, O. R. (2007). Failure to consult for symptoms of heart failure in patients with a Type-D personality. Heart, 93, 814-818.

Schumacker, R. E., \& Lomax, R. G. (2004). A beginner's guide to structural equation modeling (2nd ed.). Mahwah, NJ: Lawrence Erlbaum.

Smari, J., Olason, D. T., Arnarson, T. O., \& Sigurðsson, J. F. (2008). Mælitæki fyrir punglyndi fullorðinna sem til eru í íslenskri gerð: Próffræðilegar upplýsingar og notagildi [Icelandic translations of depression measures for adult populations: Psychometric information and usefulness]. Sálfraðiritið, 13, 147-169.

Spindler, H., Kruse, C., Zwisler, A. D., \& Pedersen, S. S. (2009). Increased anxiety and depression in Danish cardiac patients with a Type D personality: Cross-validation of the Type D scale (DS14). International Journal of Behavioral Medicine, 16, 98-107.

Strike, P. C., \& Steptoe, A. (2004). Psychosocial factors in the development of coronary artery disease. Progress in Cardiovascular Diseases, 46, 337-347.

Suls, J., \& Bunde, J. (2005). Anger, anxiety, and depression as risk factors for cardiovascular disease: The problems and implications of overlapping affective dispositions. Psychological Bulletin, 131, 260-300.

Svansdóttir, E. (2006). Pýding og próffraæðileg úttekt á DS-14 listanum: Fyrirlögn meðal háskólanema og hjartasjúklinga [Translation and psychometric evaluation of the DS-14 scale among university students and heart patients]. Unpublished cand psych thesis, University of Iceland, Reykjavik, Iceland. 
Whitehead, D. L., Perkins-Porras, L., Strike, P. C., Magid, K., \& Steptoe, A. (2007). Cortisol awakening response is elevated in acute coronary syndrome patients with Type-D personality. Journal of Psychosomatic Research, 62, 419-425.

Williams, L., O'Connor, R. C., Grubb, N. R., \& O'Carroll, R. E. (2011). Type D personality and illness perceptions in myocardial infarction patients. Journal of Psychosomatic Research, 70, 141-144.

Williams, L., O'Connor, R. C., Howard, S., Hughes, B. M., Johnston, D. W., Hay, J. L., et al. (2008). Type-D personality mechanisms of effect: The role of health-related behavior and social support. Journal of Psychosomatic Research, 64, 63-69.

Yu, X. N., Zhang, J., \& Liu, X. (2008). Application of the Type D Scale (DS14) in Chinese coronary heart disease patients and healthy controls. Journal of Psychosomatic Research, 65, 595-601.

Zigmond, A. S., \& Snaith, R. P. (1983). The hospital anxiety and depression scale. Acta Psychiatrica Scandinavica, 67, 361-370. 